\title{
Erratum to: The preventive effect of pentoxifylline on contrast-induced nephropathy: a randomized clinical trial
}

\author{
Vahideh Yavari • Mohammad Ali Ostovan • \\ Javad Kojuri - Raha Afshariani - Alireza Hamidian Jahromi • \\ Jamshid Roozbeh $\cdot$ Maryam Pakfetrat
}

Published online: 10 May 2013

(C) Springer Science+Business Media Dordrecht 2013

\section{Erratum to: Int Urol Nephrol \\ DOI 10.1007/s11255-013-0420-4}

In the original version, the name of the fifth co-author has been wrongly published as Alireza Hamidian. The correct name should be Alireza Hamidian Jahromi.

The online version of the original article can be found under doi:10.1007/s11255-013-0420-4.

\section{Yavari}

Department of Internal Medicine, School of Medicine, Shiraz University of Medical Sciences, Shiraz, Iran e-mail: yavariv@gmail.com

\section{A. Ostovan · J. Kojuri}

Department of Cardiology, School of Medicine, Shiraz University of Medical Sciences, Shiraz, Iran e-mail: ostovanm@sums.ac.ir

J. Kojuri

e-mail:kojurij@yahoo.com

\section{R. Afshariani ( $\square)$}

Department of Health and Nutrition, School of Health, Shiraz University of Medical Sciences, Shiraz, Iran e-mail: rahaafshariani@yahoo.com

\author{
A. Hamidian Jahromi \\ Department of Surgery, Louisiana State University Health \\ Sciences Cente, Shreveport, LA 71103, USA \\ e-mail: alirezahamidian@yahoo.com \\ J. Roozbeh · M. Pakfetrat \\ Shiraz Nephro-urology Research Center, \\ Shiraz University of Medical Sciences, Shiraz, Iran \\ e-mail: roozbehj@hotmail.com \\ M. Pakfetrat \\ e-mail: pakfetratm@sums.ac.ir
}

